\title{
Stability and Fitness of Pyraclostrobin- and Boscalid-Resistant Phenotypes in Field Isolates of Botrytis cinerea from Apple
}

\author{
Y. K. Kim and C. L. Xiao \\ First and second authors: Department of Plant Pathology, Washington State University, Tree Fruit Research and Extension Center, 1100 N. \\ Western Avenue, Wenatchee 98801. \\ Accepted for publication 16 June 2011.
}

\begin{abstract}
Kim, Y. K., and Xiao, C. L. 2011. Stability and fitness of pyraclostrobinand boscalid-resistant phenotypes in field isolates of Botrytis cinerea from apple. Phytopathology 101:1385-1391.

Phenotype stability, fitness, and competitive ability of pyraclostrobinand boscalid-resistant isolates of Botrytis cinerea from apple were investigated. Stability of resistance was determined after consecutive transfers on potato dextrose agar (PDA) or being cycled on apple fruit. In vitro fitness components mycelial growth, osmotic sensitivity, conidial germination, and sporulation were evaluated on agar media. Pathogenicity, virulence and sporulation on apple fruit were evaluated at both 20 and $0^{\circ} \mathrm{C}$. Competition between fungicide-resistant and -sensitive isolates on apple fruit also was evaluated. Resistance to the two fungicides was retained at levels similar to that of the initial generation after 20 and 10 transfers on PDA and five and three disease cycles on apple fruit at 20 and $0^{\circ} \mathrm{C}$, respectively. Great variability in individual fitness components tested was observed among isolates within the same phenotype groups

types except that the phenotype resistant only to boscalid produced fewer conidia in vitro than sensitive isolates. Resistant isolates were as pathogenic and virulent on apple fruit as sensitive isolates. There was no significant correlation between the values of individual fitness components tested and the level of resistance to pyraclostrobin or boscalid, except that virulence at $20^{\circ} \mathrm{C}$ positively correlated with the level of resistance to the two fungicides. The final frequency of pyraclostrobin-resistant individuals in the populations was significantly decreased compared with the initial generation and no boscalid-resistant individuals were detected after four disease cycles on apple fruit inoculated with a pair mixture of a dualsensitive isolate and one isolate each of the three phenotypes resistant to pyraclostrobin, boscalid, or both. The results suggest that resistance of $B$. cinerea to pyraclostrobin and boscalid was stable in the absence of the fungicides and that resistance to the two fungicides did not significantly impair individual fitness components tested. However, both pyraclostrobin- and boscalid-resistant isolates exhibited competitive disadvantage over the dual-sensitive isolate on apple fruit.
\end{abstract} either sensitive or resistant to the fungicides but, when compared as phenotype groups, there were no significant differences in the mean values of these fitness components between resistant and sensitive pheno-
Additional keywords: fungicide resistance, gray mold, QoI, SDHI.
Botrytis cinerea Pers. (teleomorph Botryotinia fuckeliana [de Bary] Whetzel) causes diseases on a wide variety of economically important plant species, including fruit, vegetables, and ornamentals, in the field as well as during storage (20). Gray mold caused by $B$. cinerea is one of the major postharvest diseases in apple (Malus $\times$ domestica) (31). Control of diseases caused by $B$. cinerea, including gray mold in stored apple fruit, has long been dependent on the use of fungicides $(22,34)$. However, B. cinerea is a high-risk fungal pathogen in the development of resistance to fungicides because of its short life cycle and prolific reproduction (10). Fungicide resistance in $B$. cinerea often results in the failure of disease control, and management of fungicide resistance has been an integral part of chemical control of diseases caused by $B$. cinerea (22).

Pyraclostrobin belongs to the quinone outside inhibitor (QoI) class of fungicides, which inhibits mitochondrial respiration in fungi by binding to the Qo site of the cytochrome $b c_{1}$ complex, blocking electron transfer and halting ATP synthesis (7). QoI fungicides are effective in inhibiting spore germination, mycelial growth, and sporulation of the target fungal pathogens (7). Because of their broad-spectrum activity against major groups of plant-pathogenic fungi, QoIs have been widely used in agriculture (7). However, the risk for development of resistance to QoI fungicides is high (15). Numerous pathogens from a variety of

Corresponding author: C. L. Xiao; E-mail address: clxiao@wsu.edu

doi:10.1094/PHYTO-04-11-0123

(c) 2011 The American Phytopathological Society crops, including $B$. cinerea, have developed resistance to QoI fungicides $(4,16,21,23)$. Boscalid belongs to the succinate dehydrogenase inhibitor (SDHI) class, which prevents mitochondrial respiration by inhibiting the activity of mitochondrial respiratory complex II, also known as succinate dehydrogenase (32). Boscalid is most effective against conidial germination, though it also inhibits mycelial growth (21,32). Boscalid represents a recently introduced member of SDHIs that are effective in controlling diseases caused by $B$. cinerea and many other economically important diseases (32). However, boscalid resistance has emerged in populations of some fungal pathogens, including $B$. cinerea $(2,21,23)$.

The fungicide Pristine is a premixed formulation of pyraclostrobin and boscalid. Pristine is effective in controlling diseases caused by $B$. cinerea on a wide range of crops. In apple, a nearharvest application of Pristine in the orchard is effective for controlling gray mold in stored fruit, and this practice is being increasingly implemented by apple growers for postharvest disease control in the U.S. Pacific Northwest (33). The premixed formulation Pristine, consisting of two different classes of fungicides, is intended not only to provide a broad-spectrum activity against a wide range of major plant pathogens but also to manage fungicide resistance (32). However, dual resistance to pyraclostrobin and boscalid has been detected in $B$. cinerea in apple orchards where the fungicide Pristine had been used (21). Resistance to pyraclostrobin and boscalid has also been reported in $B$. cinerea isolates from grape and kiwi $(6,23)$. Although dual resistance to pyraclostrobin and boscalid occurs in $B$. cinerea, there is no cross resistance between boscalid and pyraclostrobin (21). 
Because resistance to pyraclostrobin and boscalid has been detected in $B$. cinerea, future usefulness of these fungicides depends on the levels of persistence and build-up of fungicideresistant populations of the pathogen. Resistance stability, fitness, and competitive ability of field-resistant isolates are important factors in determining whether or not resistance may become established and the dynamics of fungicide resistance frequency in the pathogen populations $(11,27)$. A study using laboratoryinduced pyraclostrobin-resistant mutants of $B$. cinerea indicated that pyraclostrobin resistance was significantly reduced in the absence of the fungicide and that the mutants suffered significant fitness penalties in sporulation, conidial germination, and sclerotia production and were less competitive than the wild-type strain in vitro (26). Boscalid-resistant mutants of $B$. cinerea derived from UV mutagenesis in the laboratory exhibited reduced capacity in sporulation in vitro and reduced pathogenicity on eggplant leaves (Solanum melongena) (36). However, these reports were based only on laboratory-induced mutants resistant to either pyraclostrobin or boscalid. It is unknown whether these laboratory-induced resistant mutants are representative of field-resistant strains. In addition, no information is available regarding resistance stability and fitness in $B$. cinerea isolates exhibiting dual resistance to pyraclostrobin and boscalid. Because more new members of SDHI fungicides are being introduced into the market and preformulated mixtures consisting of QoIs and SDHIs are being increasingly used for control of $B$. cinerea on various crops (13), information on biological and ecological characteristics of QoI resistance and SDHI resistance in field-resistant isolates of B. cinerea is needed in order to develop relevant strategies for gray mold disease control and management of fungicide resistance in $B$. cinerea.

The objectives of this study were to (i) determine in vitro and in vivo stability of pyraclostrobin- and boscalid-resistant phenotypes of $B$. cinerea, (ii) assess whether fitness costs are associated with pyraclostrobin resistance and boscalid resistance in field fungicide-resistant isolates of $B$. cinerea, and (iii) determine in vivo competitive relationships between isolates resistant and sensitive to pyraclostrobin and boscalid.

\section{MATERIALS AND METHODS}

Fungicides and fruit. Technical-grade pyraclostrobin (98\% active ingredient [a.i.]; BASF Corporation, Research Triangle Park,
NC) and boscalid (99\% a.i.; BASF Corporation) were used for in vitro fungicide sensitivity assays in this study. The fungicides were dissolved in $100 \%$ acetone to provide stock solutions containing pyraclostrobin and boscalid at 100 and $20 \mathrm{mg} / \mathrm{ml}$, respectively.

'Red Delicious' apple fruit harvested from a commercial organic orchard located in Wenatchee, WA were used throughout this study. No fungicides had been used on the fruit in the orchard to avoid contamination by preharvest fungicide residues on the fruit. Prior to use, fruit were surface disinfested in $0.6 \%$ sodium hypochlorite solution for $5 \mathrm{~min}$, rinsed three times with deionized water, and air dried. Prior to inoculation, fruit were kept at room temperature $\left(22\right.$ to $\left.25^{\circ} \mathrm{C}\right)$ overnight.

Fungal isolates and phenotypes of fungicide resistance. In total, 14 single-spore isolates resistant to pyraclostrobin, boscalid, or both and eight single-spore isolates sensitive to both fungicides were used in this study (Tables 1 and 2). The eight isolates sensitive to both pyraclostrobin and boscalid were selected from a baseline population collected either prior to the registration of Pristine or from organic orchards where Pristine was never used (21). The 14 fungicide-resistant isolates were collected during a fungicide-resistance monitoring study carried out in 2008 and 2009 from decayed apple fruit originating from apple orchards where Pristine had been used for four consecutive years, and the sensitivity or resistance of these isolates to pyraclostrobin and boscalid had been determined (21). All isolates were stored as mycelial plugs in $15 \%$ glycerol at $-80^{\circ} \mathrm{C}$.

Because benzimidazole fungicides and the anilinopyrimidine fungicide cyprodinil had been used prior to the registration of the fungicide Pristine in these orchards from which resistant isolates were obtained, all selected isolates of $B$. cinerea used in this study also were tested for resistance to thiabendazole (benzimidazole) and pyrimethanil (anilinopyrimidine) following the procedures of Zhao et al. (35). All 22 isolates used in this study were sensitive to pyrimethanil, and seven isolates that were resistant to both pyraclostrobin and boscalid also were resistant to thiabendazole (Table 1). Because benzimidazole resistance is stable and no fitness costs are associated with benzimidazole resistance in $B$. cinerea (30), the phenotypes of the 22 isolates used in the study were characterized as either sensitive or resistant to pyraclostrobin and boscalid.

Stability of resistance. To test the stability of fungicide resistance in vitro, resistant isolates were subcultured every 2 days at

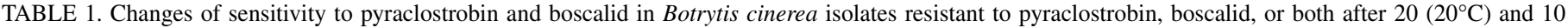
$\left(0^{\circ} \mathrm{C}\right)$ consecutive generations on fungicide-free potato dextrose agar (PDA) and after five $\left(20^{\circ} \mathrm{C}\right)$ and three $\left(0^{\circ} \mathrm{C}\right)$ disease cycles on apple fruit ${ }^{\mathrm{W}}$

\begin{tabular}{|c|c|c|c|c|c|c|c|c|c|c|c|}
\hline \multirow[b]{3}{*}{ Isolate } & \multirow[b]{3}{*}{ Phenotype ${ }^{x}$} & \multicolumn{5}{|c|}{$\mathrm{EC}_{50}$ value $(\mu \mathrm{g} / \mathrm{ml})$ of pyraclostrobin ${ }^{\mathrm{y}}$} & \multicolumn{5}{|c|}{$\mathrm{EC}_{50}$ value $(\mu \mathrm{g} / \mathrm{ml})$ of boscalid ${ }^{\mathrm{z}}$} \\
\hline & & \multirow[b]{2}{*}{ Initial } & \multicolumn{2}{|c|}{ PDA } & \multicolumn{2}{|c|}{ Fruit } & \multirow[b]{2}{*}{ Initial } & \multicolumn{2}{|c|}{ PDA } & \multicolumn{2}{|c|}{ Fruit } \\
\hline & & & $20^{\circ} \mathrm{C}$ & $0^{\circ} \mathrm{C}$ & $20^{\circ} \mathrm{C}$ & $0^{\circ} \mathrm{C}$ & & $20^{\circ} \mathrm{C}$ & $0^{\circ} \mathrm{C}$ & $20^{\circ} \mathrm{C}$ & $0^{\circ} \mathrm{C}$ \\
\hline CLX6627 & $\mathrm{Pyr}^{\mathrm{R}} \mathrm{Bos}^{\mathrm{S}}$ & 92.5 & 102.2 & 94 & 90.9 & $55.2^{*}$ & - & - & - & - & - \\
\hline CLX6628 & $\mathrm{Pyr}^{\mathrm{R}} \mathrm{Bos}^{\mathrm{S}}$ & $>100$ & $>100$ & $>100$ & $>100$ & $>100$ & - & - & - & - & - \\
\hline CLX7435 & $\mathrm{Pyr}^{\mathrm{R}} \mathrm{Bos}^{\mathrm{S}}$ & $>100$ & $>100$ & $>100$ & $>100$ & $>100$ & - & - & - & - & - \\
\hline CLX7452 & $\mathrm{Pyr}^{\mathrm{R}} \mathrm{Bos}^{\mathrm{S}}$ & 41.6 & $37.7 *$ & $31.9^{*}$ & 39.7 & $30.6^{*}$ & - & - & - & - & - \\
\hline CLX7434 & $\mathrm{Pyr}^{\mathrm{S}} \mathrm{Bos}^{\mathrm{R}}$ & - & - & - & - & - & $>20$ & $>20$ & $>20$ & $>20$ & $>20$ \\
\hline CLX7436 & $\mathrm{Pyr}^{\mathrm{S}} \mathrm{Bos}^{\mathrm{R}}$ & - & - & - & - & - & $>20$ & $>20$ & $>20$ & $>20$ & $>20$ \\
\hline CLX6632 & $\mathrm{Pyr}^{\mathrm{R}} \mathrm{Bos}^{\mathrm{R}}$ & $>100$ & $>100$ & $>100$ & $>100$ & $>100$ & 8.8 & 12.3 & 8.5 & 10.2 & 10.8 \\
\hline CLX7420 & $\mathrm{Pyr}^{\mathrm{R}} \mathrm{Bos}^{\mathrm{R}}$ & $>100$ & $>100$ & $>100$ & $>100$ & $>100$ & $>20$ & $>20$ & $>20$ & $>20$ & $>20$ \\
\hline CLX7391 & $\mathrm{Pyr}^{\mathrm{R}} \mathrm{Bos}^{\mathrm{R}}$ & $>100$ & $>100$ & $>100$ & $>100$ & $>100$ & $>20$ & $>20$ & $>20$ & $>20$ & $>20$ \\
\hline CLX7392 & $\mathrm{Pyr}^{\mathrm{R}} \mathrm{Bos}^{\mathrm{R}}$ & $>100$ & $>100$ & $>100$ & $>100$ & $>100$ & 17.5 & 16.2 & 14.5 & 15.9 & 14.5 \\
\hline CLX7451 & $\mathrm{Pyr}^{\mathrm{R}} \mathrm{Bos}^{\mathrm{R}}$ & $>100$ & $>100$ & $>100$ & $>100$ & $>100$ & 12.1 & 17.8 & 15 & 10.1 & 14.1 \\
\hline CLX7453 & $\mathrm{Pyr}^{\mathrm{R}} \mathrm{Bos}^{\mathrm{R}}$ & $>100$ & $>100$ & $>100$ & $>100$ & $>100$ & $>20$ & $>20$ & $>20$ & $>20$ & $>20$ \\
\hline CLX7465 & $\operatorname{Pyr}^{\mathrm{R}} \mathrm{Bos}^{\mathrm{R}}$ & $>100$ & $>100$ & $>100$ & $>100$ & $>100$ & $>20$ & $>20$ & $>20$ & $>20$ & $>20$ \\
\hline CLX7466 & $\operatorname{Pyr}^{R} \operatorname{Bos}^{R}$ & $>100$ & $>100$ & $>100$ & $>100$ & $>100$ & $>20$ & $>20$ & $>20$ & $>20$ & $>20$ \\
\hline
\end{tabular}

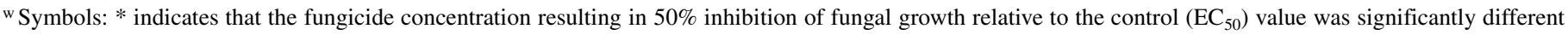
from that of the initial value according to a $t$ test at $P=0.05$ and - indicates no data for this item. Only the isolates resistant to the fungicide were tested. ${ }^{x} \mathrm{Pyr}=$ pyraclostrobin, $\mathrm{Bos}=$ boscalid, $\mathrm{R}=$ resistant, $\mathrm{S}=$ sensitive.

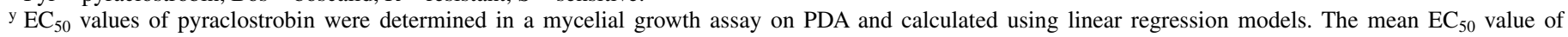
pyraclostrobin for sensitive isolates in the baseline population is $0.043 \mu \mathrm{g} / \mathrm{ml}(21)$.

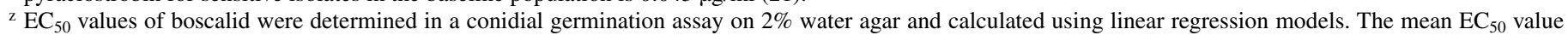
of boscalid for sensitive isolates in the baseline population is $0.631 \mu \mathrm{g} / \mathrm{ml}(21)$. 
$20^{\circ} \mathrm{C}$ for 20 successive generations and every 10 days at $0^{\circ} \mathrm{C}$ for 10 generations on fungicide-free potato dextrose agar (PDA; Difco Laboratories, Detroit). Fungicide concentration resulting in $50 \%$ inhibition of fungal growth relative to the control $\left(\mathrm{EC}_{50}\right)$ values of the fungicide for the initial generation and final generation of each isolate were determined based on the sensitivity to the fungicide. Sensitivity to pyraclostrobin was tested in a mycelial growth assay on PDA amended with pyraclostrobin at 0 , $0.0005,0.005,0.01,0.05,0.1,0.5,1,5,10,50$, and $100 \mu \mathrm{g} / \mathrm{ml}$ according to the procedure of Kim and Xiao (21). Concentrations $\leq 1 \mu \mathrm{g} / \mathrm{ml}$ were used for sensitive isolates, and the latter six concentrations (plus the nonamended control) were used to test resistant isolates. A conidial germination assay is preferred for phenotyping isolates of $B$. cinerea for resistance to boscalid (21); therefore, sensitivity to boscalid was determined in a conidial germination assay on water agar amended with boscalid at 0 , $0.01,0.1,0.25,0.5,1,2.5,5,10$, and $20 \mu \mathrm{g} / \mathrm{ml}$, and the latter two concentrations were included only in the tests for resistant isolates. For each isolate, four replicate plates were used.

To test in vivo stability, fruit prepared as described above were wounded with a sterilized finish-nail head $(3 \mathrm{~mm}$ in depth and $4 \mathrm{~mm}$ in diameter) and inoculated with $20 \mu \mathrm{l}$ of conidial suspension $\left(1 \times 10^{5}\right.$ conidia $\left./ \mathrm{ml}\right)$. Four inoculated fruit per isolate were placed on fiberboard apple trays in a cardboard apple box wrapped in a perforated polyethylene bag and stored at $20^{\circ} \mathrm{C}$ for 7 days and $0^{\circ} \mathrm{C}$ for 30 days. The fungus was reisolated from one of the decayed fruit for each isolate onto PDA and cultures were incubated at $20^{\circ} \mathrm{C}$. After 3 days of incubation, mycelia produced on the plates were used as inoculum for inoculating apple fruit for the following generation. Mycelial plugs ( $4 \mathrm{~mm}$ in diameter) were cut from the margin of actively growing colonies of each isolate with a sterile cork borer, and each apple fruit was wounded as described above and inoculated by placing one mycelial plug upside down at the wound. A piece $\left(\approx 2\right.$ by $\left.2 \mathrm{~cm}^{2}\right)$ of two-layer moist cheesecloth was placed on the top of the wound to maintain moisture. Fruit were stored as described above. After five and three disease cycles at 20 and $0^{\circ} \mathrm{C}$, respectively, $\mathrm{EC}_{50}$ values of pyraclostrobin or boscalid for the final generation for each isolate were determined and compared with that of the initial generation as described above.

Saprophytic fitness components. The following fitness components were determined in vitro for saprophytic ability of resistant and sensitive isolates of $B$. cinerea: (i) mycelial growth on PDA at 20 and $0^{\circ} \mathrm{C}$, (ii) spore production on PDA, (iii) osmotic sensitivity, and (iv) germination ability on $2 \%$ water agar.

Mycelial growth. Isolates were retrieved from stock cultures stored at $-80^{\circ} \mathrm{C}$ and subcultured on PDA to prepare inoculum. After 2 days of incubation at $20^{\circ} \mathrm{C}$ in the dark, a 5-mm-diameter mycelial plug was cut from the margin of actively growing colonies of each isolate with a sterile cork borer and placed upside down at the center of PDA plate. For each isolate, one set of four plates were incubated at $20^{\circ} \mathrm{C}$ for 3 days and the other set of four plates were incubated at $0^{\circ} \mathrm{C}$ for 14 days in the dark. Colony diameters were then measured at two perpendicular directions.

Spore production. Mycelial plugs were cut from the leading edges of colonies on 2-day-old PDA cultures and placed upside down at the center of PDA plates. The plates were incubated at $20^{\circ} \mathrm{C}$ for 2 to 3 days in the dark and then placed under $12 \mathrm{~h}$ of fluorescent light $\left(5 \mathrm{w} / \mathrm{m}^{2}\right)$ and $12 \mathrm{~h}$ of darkness for 14 days to facilitate spore production. Each plate was flooded with $20 \mathrm{ml}$ of sterile deionized water, and the conidial suspension was filtered through two layers of cheesecloth. The number of conidia in the suspension was estimated with the aid of a hemacytometer. Four replicates for each isolate and four droplets of the suspension per replicate were counted.

Osmotic sensitivity. Sensitivity to osmotic stress may be related to the change in cell wall composition; thereby, the fitness of resistant isolates that are more sensitive to osmotic stress than fungicide-sensitive isolates may be decreased in the field (8). To test osmotic sensitivity, a 5-mm-diameter mycelial plug grown on 2-day-old PDA was taken from the margin of actively growing colonies of each isolate and placed upside down at the center of PDA or PDA amended with $8 \% \mathrm{NaCl}$. After 3 days of incubation at $20^{\circ} \mathrm{C}$ in the dark, colony diameters were measured at two perpendicular directions. The percentage of mycelial growth inhibition was calculated using the formula percent inhibition $=(1-$

TABLE 2. Saprophytic fitness components of Botrytis cinerea isolates resistant or sensitive to pyraclostrobin, boscalid, or both ${ }^{\mathrm{V}}$

\begin{tabular}{|c|c|c|c|c|c|c|}
\hline \multirow[b]{2}{*}{ Isolate } & \multirow[b]{2}{*}{ Phenotype $^{\mathrm{w}}$} & \multicolumn{2}{|c|}{ Mycelial growth (mm) } & \multirow[b]{2}{*}{ Spore production $^{\mathrm{x}}$} & \multirow[b]{2}{*}{ Osmotic sensitivity } & \multirow[b]{2}{*}{ Germination $^{\mathrm{z}}$} \\
\hline & & $20^{\circ} \mathrm{C}$ & $0^{\circ} \mathrm{C}$ & & & \\
\hline CLX6627 & $\mathrm{Pyr}^{\mathrm{R}} \mathrm{Bos}{ }^{\mathrm{S}}$ & $56.1 \mathrm{a}$ & $47.8 \mathrm{fg}$ & 5.57 cde & $87.6 \mathrm{e}$ & 96.6 cde \\
\hline CLX6628 & $\mathrm{Pyr}^{\mathrm{R}} \mathrm{Bos}^{\mathrm{S}}$ & $53.4 \mathrm{de}$ & 48.7 efg & $5.65 \mathrm{bc}$ & $94.0 \mathrm{~b}$ & $98.5 \mathrm{a}$ \\
\hline CLX7435 & $\mathrm{Pyr}^{\mathrm{R}} \mathrm{Bos}^{\mathrm{S}}$ & $56.1 \mathrm{a}$ & $44.1 \mathrm{~h}$ & $5.44 \mathrm{~g}$ & $83.1 \mathrm{j}$ & $94.3 \mathrm{fgh}$ \\
\hline CLX7452 & $\mathrm{Pyr}^{\mathrm{R}} \mathrm{Bos}^{\mathrm{S}}$ & $47.1 \mathrm{j}$ & $59.3 \mathrm{a}$ & $6.03 \mathrm{a}$ & $86.5 \mathrm{fg}$ & 96.6 cde \\
\hline CLX7434 & $\mathrm{Pyr}^{\mathrm{S}} \mathrm{Bos}^{\mathrm{R}}$ & $47.0 \mathrm{j}$ & $48.1 \mathrm{efg}$ & $4.48 \mathrm{j}$ & $93.6 \mathrm{~b}$ & $97.4 \mathrm{abc}$ \\
\hline CLX7436 & $\mathrm{Pyr}^{\mathrm{S}} \mathrm{Bos}^{\mathrm{R}}$ & $48.0 \mathrm{i}$ & $38.3 \mathrm{i}$ & $5.44 \mathrm{~g}$ & $90.1 \mathrm{~d}$ & $89.9 \mathrm{j}$ \\
\hline CLX6632 & $\mathrm{Pyr}^{\mathrm{R}} \mathrm{Bos}^{\mathrm{R}}$ & $51.6 \mathrm{~h}$ & $48.7 \mathrm{efg}$ & $5.33 \mathrm{~h}$ & $84.4 \mathrm{i}$ & $96.9 \mathrm{bcd}$ \\
\hline CLX7420 & $\mathrm{Pyr}^{\mathrm{R}} \mathrm{Bos}^{\mathrm{R}}$ & $51.3 \mathrm{~h}$ & $37.1 \mathrm{i}$ & $5.65 \mathrm{bc}$ & $90.3 \mathrm{~d}$ & $96.5 \mathrm{bcd}$ \\
\hline CLX7391 & $\mathrm{Pyr}^{\mathrm{R}} \mathrm{Bos}^{\mathrm{R}}$ & $51.9 \mathrm{gh}$ & $52.7 \mathrm{c}$ & $5.56 \mathrm{cdef}$ & $84.8 \mathrm{hi}$ & $97.0 \mathrm{bcd}$ \\
\hline CLX7392 & $\mathrm{Pyr}^{\mathrm{R}} \mathrm{Bos}^{\mathrm{R}}$ & $46.1 \mathrm{kl}$ & $46.6 \mathrm{gh}$ & $5.50 \mathrm{efg}$ & $90.7 \mathrm{~d}$ & $95.4 \mathrm{defg}$ \\
\hline CLX7451 & $\mathrm{Pyr}^{\mathrm{R}} \mathrm{Bos}^{\mathrm{R}}$ & 45.61 & 50.4 cde & $5.56 \mathrm{cdef}$ & $84.8 \mathrm{hi}$ & $96.5 \mathrm{abc}$ \\
\hline CLX7453 & $\mathrm{Pyr}^{\mathrm{R}} \mathrm{Bos}^{\mathrm{R}}$ & $52.4 \mathrm{fg}$ & $52.6 \mathrm{c}$ & $5.68 \mathrm{~b}$ & $79.6 \mathrm{k}$ & $96.0 \mathrm{cdef}$ \\
\hline CLX7465 & $\mathrm{Pyr}^{\mathrm{R}} \mathrm{Bos}^{\mathrm{R}}$ & $53.9 \mathrm{~cd}$ & $50.5 \mathrm{cde}$ & $5.63 \mathrm{bcd}$ & $84.0 \mathrm{ij}$ & $92.8 \mathrm{ghi}$ \\
\hline CLX7466 & $\mathrm{Pyr}^{\mathrm{R}} \mathrm{Bos}^{\mathrm{R}}$ & $52.8 \mathrm{ef}$ & $49.6 \mathrm{def}$ & $5.55 \mathrm{cdef}$ & $80.1 \mathrm{k}$ & $94.6 \mathrm{efg}$ \\
\hline CLX1924 & $\mathrm{Pyr}^{\mathrm{S}} \mathrm{Bos}{ }^{\mathrm{S}}$ & $56.0 \mathrm{a}$ & 50.4 cde & $5.55 \mathrm{cdef}$ & $86.7 \mathrm{efg}$ & $95.6 \mathrm{cdef}$ \\
\hline CLX1749 & $\mathrm{Pyr}^{\mathrm{S}} \mathrm{Bos}^{\mathrm{S}}$ & $53.5 \mathrm{cde}$ & $49.3 \mathrm{ef}$ & $5.44 \mathrm{~g}$ & $84.8 \mathrm{hi}$ & $91.1 \mathrm{ij}$ \\
\hline CLX1753 & $\mathrm{Pyr}^{\mathrm{S}} \mathrm{Bos}^{\mathrm{S}}$ & $54.3 \mathrm{c}$ & $52.9 \mathrm{c}$ & $5.32 \mathrm{~h}$ & $83.9 \mathrm{ij}$ & 91.4 hij \\
\hline CLX1760 & $\mathrm{Pyr}^{\mathrm{S}} \mathrm{Bos}{ }^{\mathrm{S}}$ & $52.8 \mathrm{ef}$ & $49.8 \mathrm{def}$ & $5.52 \mathrm{efg}$ & $85.8 \mathrm{gh}$ & $97.5 \mathrm{abc}$ \\
\hline CLX1853 & $\mathrm{Pyr}^{\mathrm{S}} \mathrm{Bos}{ }^{\mathrm{S}}$ & $56.3 \mathrm{a}$ & $52.0 \mathrm{~cd}$ & $5.47 \mathrm{fg}$ & 87.5 ef & $94.1 \mathrm{fgh}$ \\
\hline CLX6635 & $\mathrm{Pyr}^{\mathrm{S}} \mathrm{Bos}^{\mathrm{S}}$ & $55.1 \mathrm{~b}$ & $49.8 \mathrm{def}$ & $5.04 \mathrm{i}^{\circ}$ & 87.1 ef & 93.9 fghi \\
\hline CLX6691 & $\mathrm{Pyr}^{\mathrm{S}} \mathrm{Bos}^{\mathrm{S}}$ & $48.6 \mathrm{i}$ & $52.8 \mathrm{c}$ & 5.57 cde & $92.7 \mathrm{c}$ & $97.4 \mathrm{abc}$ \\
\hline CLX6703 & $\mathrm{Pyr}^{\mathrm{S}} \mathrm{Bos}^{\mathrm{S}}$ & $46.6 \mathrm{jk}$ & $56.8 \mathrm{~b}$ & 5.58 bcde & $100 \mathrm{a}$ & $97.9 \mathrm{ab}$ \\
\hline
\end{tabular}

${ }^{v}$ Values followed by the same lowercase letter within a column are not significantly different at $K$ ratio $=100(P=0.05)$ according to the Waller-Duncan $t$ test.

${ }^{\mathrm{w}} \mathrm{Pyr}=$ pyraclostrobin, Bos $=$ boscalid, $\mathrm{R}=$ resistant, $\mathrm{S}=$ sensitive.

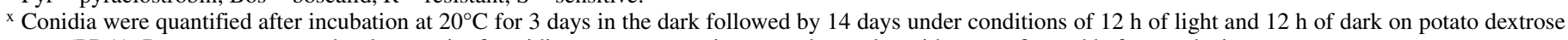
agar (PDA). Data were presented as $\log _{10}$ unit of conidia per square centimeter and were logarithm transformed before analysis.

y Percent inhibition of mycelial growth on PDA amended with $8 \% \mathrm{NaCl}$ relative to the nonamended control. Data were arcsine-transformed before analysis.

${ }^{\mathrm{z}}$ Percent germination was determined on $2 \%$ water agar after $12 \mathrm{~h}$ of incubation at $20^{\circ} \mathrm{C}$. Data were arcsine-transformed before analysis. 
$[\mathrm{A} / \mathrm{N}]) \times 100$, where $\mathrm{A}$ is the mean colony diameter of colonies grown on PDA amended with $8 \% \mathrm{NaCl}$ and $\mathrm{N}$ is that on nonamended PDA. For each isolate, four replicate plates were used.

Conidial germination. Conidia from the spore-production experiment described above were used as inoculum for this experiment. A $100-\mu$ l aliquot of the conidial suspension $\left(2 \times 10^{5}\right.$ conidia/ml) was spread on a petri plate containing $2 \%$ water agar, and plates were incubated at $20^{\circ} \mathrm{C}$ in the dark for $12 \mathrm{~h}$. Four plates per replicate were used for each isolate. Percent germination was determined by examining 100 conidia per plate. A conidium was considered germinated if the germ tube is at least the length of the conidium.

Pathogenic fitness components. Pathogenicity (the ability to cause decay on fruit) and virulence (the size of decay on fruit) of isolates exhibiting different fungicide-resistance phenotypes were evaluated on Red Delicious apple fruit. Fruit were prepared for inoculation as described above. Fruit were wounded with a finishnail head and inoculated with $20 \mu$ of the conidial suspension $\left(1 \times 10^{5}\right.$ conidia/ml $)$. Inoculated fruit were placed on fiberboard apple trays in apple boxes wrapped in perforated polyethylene bags. For each isolate, one set of 10 fruit was incubated at room temperature $\left(22-25^{\circ} \mathrm{C}\right)$ for 7 days and the other set of 20 fruit were incubated at $0^{\circ} \mathrm{C}$ for 8 weeks. Lesion diameters were measured. The experiment was conducted three times.

Sporulation of fungicide-resistant and -sensitive isolates also was evaluated on apple fruit. Fruit were surface disinfested and inoculated with the conidial suspension as described above. Two sets, each with four replicate fruit per isolate, were inoculated as described above. One set of fruit was placed on an aluminum baking tray ( 25 by 17 by $4 \mathrm{~cm}$ ) and placed in a plastic box ( 32 by 26 by $10 \mathrm{~cm}$ ) (Pioneer Plastics, Inc., Dixon, KY) containing $\approx 200 \mathrm{ml}$ of sterile water in the bottom to maintain high humidity and incubated at $20^{\circ} \mathrm{C}$ for 10 days. After the 10 days, a piece of decayed tissue ( 2 by $2 \mathrm{~cm}^{2}$ and $3 \mathrm{~mm}$ in thickness) was cut from the fruit with a sterile scalpel and placed in a $95-\mathrm{mm}$ petri plate with two layers of moist cheesecloth on the bottom of the plate to maintain high relative humidity. Plates were placed under $12 \mathrm{~h}$ of fluorescent light $\left(5 \mathrm{w} / \mathrm{m}^{2}\right)$ and $12 \mathrm{~h}$ of darkness at $20^{\circ} \mathrm{C}$ for 7 days to facilitate sporulation. The other set of the fruit was placed on fiberboard apple trays in an apple box and incubated at $0^{\circ} \mathrm{C}$ for 6 weeks to induce sporulation. At the end of incubation periods at 0 and $20^{\circ} \mathrm{C}$, all decayed tissue in each piece was then placed in $10 \mathrm{ml}$ of deionized water in a test tube and vortexed to dislodge the conidia produced on the tissue. Four droplets of the conidial

TABLE 3. Competition between the Botrytis cinerea isolates resistant to pyraclostrobin, boscalid, or both and a dual-sensitive isolate co-inoculated on apple fruit with three different initial ratios of conidia for four disease cycles

\begin{tabular}{lcccc}
\hline & & \multicolumn{2}{c}{ Final resistance frequency $(\%)^{\mathrm{z}}$} \\
\cline { 3 - 5 } Isolate & Phenotype $^{\mathrm{x}}$ & ${\text { Initial }(\%)^{\mathrm{y}}}$ & Pyraclostrobin & Boscalid \\
\hline CLX7452 & Pyr $^{\mathrm{R}} \mathrm{Bos}^{\mathrm{S}}$ & 75 & $6.2^{*}$ & - \\
& & 50 & $10.8^{*}$ & - \\
CLX7436 & & 25 & $11.7^{*}$ & - \\
& Pyr $^{\mathrm{S}} \mathrm{Bos}^{\mathrm{R}}$ & 75 & - & 0 \\
& & 50 & - & 0 \\
CLX7466 & & 25 & - & 0 \\
& Pyr $^{\mathrm{R}} \mathrm{Bos}^{\mathrm{R}}$ & 75 & $7^{*}$ & 0 \\
& & 50 & $3.4^{*}$ & 0 \\
& & 25 & $3.6^{*}$ & 0 \\
\hline
\end{tabular}

${ }^{\mathrm{x}} \mathrm{Pyr}=$ pyraclostrobin, $\mathrm{Bos}=$ boscalid, $\mathrm{R}=$ resistant, $\mathrm{S}=$ sensitive.

${ }^{y}$ Initial resistance frequency was the ratio of conidia of the resistant isolate versus the dual-sensitive isolate (CLX1749) in the initial inoculum mixture for inoculation of apple fruit.

${ }^{z}$ Discrimination between resistant and sensitive isolates was determined with pyraclostrobin at $5 \mu \mathrm{g} / \mathrm{ml}$ in a mycelial growth assay and with boscalid at $5 \mu \mathrm{g} / \mathrm{ml}$ in a conidial germination assay (21). Symbols: * indicates that the final resistance frequency was significantly different from that of the initial resistance frequency according to a $\chi^{2}$ test at $P=0.05$ and - indicates no data for this item. Only the isolates resistant to the fungicide were tested. suspension per replicate were sampled to determine spore density in the conidial suspension with the aid of a hemacytometer. The number of conidia per square centimeter of decayed tissue was then calculated.

Competitive ability in vivo. Three resistant isolates (CLX7452, CLX7436, and CLX7466) with different fungicide-resistance phenotypes and one dual-sensitive isolate (CLX1749) were used in this experiment (Table 3). The isolates were cultured for 2 weeks on PDA for conidial production and conidial suspensions were prepared as described above. The final concentration was adjusted to $1 \times 10^{5}$ conidia $/ \mathrm{ml}$ with the aid of a hemacytometer. Each resistant isolate was mixed with the sensitive isolate by appropriate volumes of conidial suspensions to make inoculum mixtures consisting of different ratios of the resistant (R) isolates with the sensitive (S) isolate $(75 \% \mathrm{R}: 25 \% \mathrm{~S}, 50 \% \mathrm{R}: 50 \% \mathrm{~S}$, and $25 \% \mathrm{R}: 75 \% \mathrm{~S}$ ). Fruit were prepared, wounded, and inoculated as described in the in vivo sporulation study. Inoculated fruit were placed on aluminum baking trays in plastic boxes each containing $\approx 200 \mathrm{ml}$ of water in the bottom to maintain high relative humidity and incubated at $20^{\circ} \mathrm{C}$ for 10 days. Pieces $\left(2\right.$ by $2 \mathrm{~cm}^{2}$ and $3 \mathrm{~mm}$ in thickness) of decayed tissue were removed from inoculated fruit and sporulation was assessed as described in the in vivo sporulation study. Conidia produced on each piece of decayed tissue were collected into $10 \mathrm{ml}$ of sterile water and used as inoculum for inoculating fruit for the following disease cycle. Four replicate fruit per isolate-mixture treatment were used. After four disease cycles on fruit, conidia produced on decayed tissue were used for single-spore isolations, and 50 single-spore isolates from each of the four replicates per treatment were selected to determine the percentage of fungicide-resistant individuals in the final populations. Fungicide-resistance phenotypes of individual isolates were determined in a mycelial growth assay on PDA amended with the discriminatory concentration of $5 \mu \mathrm{g} / \mathrm{ml}$ for pyraclostrobin and in a conidial germination assay on water agar amended with the discriminatory concentration of $5 \mu \mathrm{g} / \mathrm{ml}$ for boscalid following the procedure described by Kim and Xiao (21). Isolates that were able to grow or germinate on the fungicide-amended media were considered resistant, and those that were completely inhibited at the discriminatory concentration were classified as sensitive (21).

Statistical analysis. All experiments were conducted at least twice. Analysis of variance using PROC analysis of variance (ANOVA) in SAS (version 9.2; SAS Institute, Inc., Cary, NC) was used to determine whether data across the runs of each experiment could be pooled. The test indicated that there were no interactions between run and variables $(P>0.05)$ and, thus, all further analyses were conducted on pooled data. The percent inhibition of mycelial growth or conidial germination relative to the control against the logarithm of each concentration of the fungicides was plotted, and linear trends were evident. The linear regression procedure REG in SAS was used to obtain regression models. In some instances, if more than one low or high concentration resulted in similar inhibitory responses at the low end or high end of the dose-response plot, the data at these lower or higher concentrations were not included in the regression analysis. $\mathrm{EC}_{50}$ values were calculated based on the regression models. To compare the $\mathrm{EC}_{50}$ values of pyraclostrobin and boscalid after successive generations on fungicide-free media and apple fruit, a $t$ test was performed using SAS. All data for each fitness component were subjected to ANOVA and the means were separated by the Waller-Duncan test $(K=100)$. The means of each group with different fungicide-resistance phenotypes were compared using a Tukey-Kramer test and means were separated by the minimum significant difference. All data in percentage were arcsinetransformed prior to analysis (18). In the competition experiments, the final frequencies of resistant isolates after four generations on fruit were compared with those of the initial resistance frequency using a $\chi^{2}$ test with SAS PROC FREQ. 


\section{RESULTS}

Stability of resistance. After successive transfers on PDA and cycling on apple fruit, the vast majority of pyraclostrobin-resistant isolates retained the same levels of $\mathrm{EC}_{50}$ values of pyraclostrobin as their initial generations, with a few exceptions (Table 1). The isolate CLX7452 showed a reduced $\mathrm{EC}_{50}$ value of pyraclostrobin after being subcultured on PDA at both 20 and $0^{\circ} \mathrm{C}$ and being cycled on fruit at $0^{\circ} \mathrm{C}$. A reduced $\mathrm{EC}_{50}$ value of pyraclostrobin was also observed in the isolate CLX6627 after three disease cycles on fruit at $0^{\circ} \mathrm{C}$. However, these two isolates retained resistance to pyraclostrobin, despite the slight reduction in $\mathrm{EC}_{50}$ values at these conditions. All boscalid-resistant isolates retained at the same levels of resistance as the initial generations in both in vitro and in vivo at 20 and $0^{\circ} \mathrm{C}$ (Table 1).

Saprophytic and pathogenic fitness. Four components of saprophytic fitness were measured for the 22 isolates of $B$. cinerea showing different phenotypes of sensitivity to pyraclostrobin and boscalid (Table 2). There was great variability in mycelial growth, spore production, and sensitivity to osmotic stress among isolates sensitive to both pyraclostrobin and boscalid as well as among isolates resistant to pyraclostrobin, boscalid, or both. When compared as phenotype groups, however, there were no significant differences in average mycelial growth, spore production, osmotic sensitivity, and conidial germination among the phenotype groups, except that the phenotype resistant only to boscalid produced fewer conidia in vitro compared with other phenotype groups.

Regardless of fungicide-resistance phenotypes of isolates tested in this study, all inoculated fruit developed symptoms of gray mold at both 0 and $20^{\circ} \mathrm{C}$ or room temperature, indicating that there were no significant differences in pathogenicity between resistant and sensitive isolates (data not shown). Isolates within each fungicide-resistance phenotype group varied in virulence (lesion size on apple fruit) and sporulation at both $20^{\circ} \mathrm{C}$ or room

TABLE 4. Pathogenic fitness components of Botrytis cinerea isolates resistant or sensitive to pyraclostrobin, boscalid, or both on apple fruit ${ }^{\mathrm{w}}$

\begin{tabular}{|c|c|c|c|c|c|}
\hline \multirow[b]{2}{*}{ Isolate } & \multirow[b]{2}{*}{ Phenotype $^{\mathrm{x}}$} & \multicolumn{2}{|c|}{ Virulence $^{y}$} & \multicolumn{2}{|c|}{ Sporulation $^{\mathrm{z}}$} \\
\hline & & RT & $0^{\circ} \mathrm{C}$ & $20^{\circ} \mathrm{C}$ & $0^{\circ} \mathrm{C}$ \\
\hline CLX6627 & $\mathrm{Pyr}^{\mathrm{R}} \mathrm{Bos}^{\mathrm{S}}$ & $59.0 \mathrm{~cd}$ & 72.7 cde & $4.78 \mathrm{ghi}$ & $1.20 \mathrm{c}$ \\
\hline CLX6628 & $\mathrm{Pyr}^{\mathrm{R}} \mathrm{Bos}^{\mathrm{S}}$ & $51.8 \mathrm{efg}$ & $66.8 \mathrm{ef}$ & $5.11 \mathrm{~b}$ & $4.39 \mathrm{a}$ \\
\hline CLX7435 & $\mathrm{Pyr}^{\mathrm{R}} \mathrm{Bos}^{\mathrm{S}}$ & $68.6 \mathrm{ab}$ & $95.3 \mathrm{a}$ & $4.67 \mathrm{ij}$ & $1.68 \mathrm{bc}$ \\
\hline CLX7452 & $\mathrm{Pyr}^{\mathrm{R}} \mathrm{Bos}^{\mathrm{S}}$ & $31.0 \mathrm{hi}$ & $51.6 \mathrm{~g}$ & $4.53 \mathrm{k}$ & $0.00 \mathrm{~d}$ \\
\hline CLX7434 & $\mathrm{Pyr}^{\mathrm{S}} \mathrm{Bos}^{\mathrm{R}}$ & $48.0 \mathrm{~g}$ & 73.8 bcde & 4.001 & $2.13 \mathrm{bc}$ \\
\hline CLX7436 & $\mathrm{Pyr}^{\mathrm{S}} \mathrm{Bos}^{\mathrm{R}}$ & $48.4 \mathrm{~g}$ & $48.8 \mathrm{~g}$ & $4.93 \mathrm{def}$ & $0.00 \mathrm{~d}$ \\
\hline CLX6632 & $\mathrm{Pyr}^{\mathrm{R}} \mathrm{Bos}^{\mathrm{R}}$ & $56.2 \mathrm{def}$ & $38.0 \mathrm{~h}$ & 4.69 hij & $1.94 \mathrm{bc}$ \\
\hline CLX7420 & $\mathrm{Pyr}^{\mathrm{R}} \mathrm{Bos}^{\mathrm{R}}$ & $36.0 \mathrm{~h}$ & $50.5 \mathrm{~g}$ & $4.64 \mathrm{jk}$ & $0.00 \mathrm{~d}$ \\
\hline CLX7391 & $\mathrm{Pyr}^{\mathrm{R}} \mathrm{Bos}^{\mathrm{R}}$ & $29.0 \mathrm{i}$ & $49.2 \mathrm{~g}$ & $5.04 \mathrm{bcd}$ & $2.06 \mathrm{bc}$ \\
\hline CLX7392 & $\mathrm{Pyr}^{\mathrm{R}} \mathrm{Bos}^{\mathrm{R}}$ & $60.7 \mathrm{~cd}$ & 78.4 bcd & $4.71 \mathrm{hij}$ & $4.07 \mathrm{a}$ \\
\hline CLX7451 & $\mathrm{Pyr}^{\mathrm{R}} \mathrm{Bos}^{\mathrm{R}}$ & $56.8 \mathrm{cde}$ & $82.3 \mathrm{~b}$ & $5.14 \mathrm{~b}$ & $4.36 \mathrm{a}$ \\
\hline CLX7453 & $\mathrm{Pyr}^{\mathrm{R}} \mathrm{Bos}^{\mathrm{R}}$ & $70.4 \mathrm{a}$ & $70.5 \mathrm{def}$ & $4.94 \mathrm{def}$ & $4.21 \mathrm{a}$ \\
\hline CLX7465 & $\mathrm{Pyr}^{\mathrm{R}} \mathrm{Bos}^{\mathrm{R}}$ & $62.9 \mathrm{bc}$ & 74.0 bcde & $5.16 \mathrm{ab}$ & $4.28 \mathrm{a}$ \\
\hline CLX7466 & $\mathrm{Pyr}^{\mathrm{R}} \mathrm{Bos}^{\mathrm{R}}$ & $70.0 \mathrm{a}$ & $80.5 \mathrm{bc}$ & $5.28 \mathrm{a}$ & $4.49 \mathrm{a}$ \\
\hline CLX1924 & $\operatorname{Pyr}^{\mathrm{S}} \mathrm{Bos}{ }^{\mathrm{S}}$ & $49.9 \mathrm{fg}$ & 67.1 ef & $5.08 \mathrm{bc}$ & $1.33 \mathrm{c}$ \\
\hline CLX1749 & $\mathrm{Pyr}^{\mathrm{S}} \mathrm{Bos} \mathrm{S}$ & $36.1 \mathrm{~h}$ & $70.4 \mathrm{def}$ & $4.89 \mathrm{efg}$ & $3.97 \mathrm{a}$ \\
\hline CLX1753 & $\mathrm{Pyr}^{\mathrm{S}} \mathrm{Bos}^{\mathrm{S}}$ & 57.7 cde & 72.8 cde & $5.17 \mathrm{ab}$ & $1.35 \mathrm{c}$ \\
\hline CLX1760 & $\mathrm{Pyr}^{\mathrm{S}} \mathrm{Bos}{ }^{\mathrm{S}}$ & $45.9 \mathrm{~g}$ & $62.2 \mathrm{f}$ & $5.00 \mathrm{cde}$ & $2.19 \mathrm{bc}$ \\
\hline CLX1853 & $\mathrm{Pyr}^{\mathrm{S}} \mathrm{Bos} \mathrm{S}$ & $48.9 \mathrm{~g}$ & 69.0 ef & $4.81 \mathrm{fgh}$ & $2.75 \mathrm{~b}$ \\
\hline CLX6635 & $\mathrm{Pyr}^{\mathrm{S}} \mathrm{Bos} \mathrm{S}$ & $47.6 \mathrm{~g}$ & $61.5 \mathrm{f}$ & $4.73 \mathrm{hij}$ & $1.77 \mathrm{bc}$ \\
\hline CLX6691 & $\mathrm{Pyr}^{\mathrm{S}} \mathrm{Bos} \mathrm{S}$ & $27.0 \mathrm{i}$ & $50.9 \mathrm{~g}$ & $4.79 \mathrm{ghi}$ & $0 \mathrm{~d}$ \\
\hline CLX6703 & $\operatorname{Pyr}^{\mathrm{S}} \mathrm{Bos}^{\mathrm{S}}$ & $19.4 \mathrm{j}$ & $36.6 \mathrm{~h}$ & $3.80 \mathrm{~m}$ & $0 \mathrm{~d}$ \\
\hline
\end{tabular}

${ }^{\text {w}}$ Values within the same column with the same lowercase letter are not significantly different at $K$ ratio $=100(P=0.05)$ according to the WallerDuncan $t$ test.

x $\mathrm{Pyr}=$ pyraclostrobin, Bos = boscalid, $\mathrm{R}=$ resistant, $\mathrm{S}=$ sensitive.

${ }^{y}$ Lesion size (virulence) was measured after incubation at room temperature (RT) $\left(22\right.$ to $\left.25^{\circ} \mathrm{C}\right)$ for 7 days and at $0^{\circ} \mathrm{C}$ for 8 weeks.

${ }^{\mathrm{z}}$ Data were presented as $\log _{10}$ unit of conidia per square centimeter and were logarithm-transformed before analysis. temperature and $0^{\circ} \mathrm{C}$ (Table 4). However, when they were compared as phenotype groups, there were no significant differences in mean values of virulence on apple fruit and sporulation on the decayed tissue among different phenotype groups. Both virulence on apple fruit at room temperature and in vivo sporulation at $20^{\circ} \mathrm{C}$ were highly correlated with those at $0^{\circ} \mathrm{C}$ (virulence: $r=0.72, P=$ 0.0001 ; sporulation: $r=0.48, P=0.0222$ ).

Correlation between individual fitness components and the level of resistance expressed as $\mathrm{EC}_{50}$ values of pyraclostrobin and boscalid were assessed. For mycelial growth, sporulation on apple fruit, spore production on PDA, osmotic sensitivity, and conidial germination, there was no significant correlation $(P>0.05)$ between the respective fitness parameters and the level of resistance to pyraclostrobin or boscalid (data not shown). A positive correlation between virulence and concentration of pyraclostrobin $(r=$ $0.50, P=0.03)$ and boscalid $(r=0.49, P=0.04)$ was observed at room temperature but not at $0^{\circ} \mathrm{C}$ (Fig. 1).

Competitive ability on apple fruit. Regardless of the phenotypes and ratios of fungicide-resistant and -sensitive isolates in the initial inoculum mixture, pyraclostrobin-resistant individuals were detectable in the populations but the frequency of pyraclostrobin-resistant individuals in the populations significantly decreased after being cycled for four generations on apple fruit compared with the initial resistance frequency (Table 3). However, no boscalid-resistant individuals in the populations were observed after being cycled for four generations on apple fruit.

\section{DISCUSSION}

In this study, we investigated the stability of pyraclostrobin resistance and boscalid resistance, fitness, and competitive ability of field-resistant isolates of B. cinerea. To our knowledge, this is
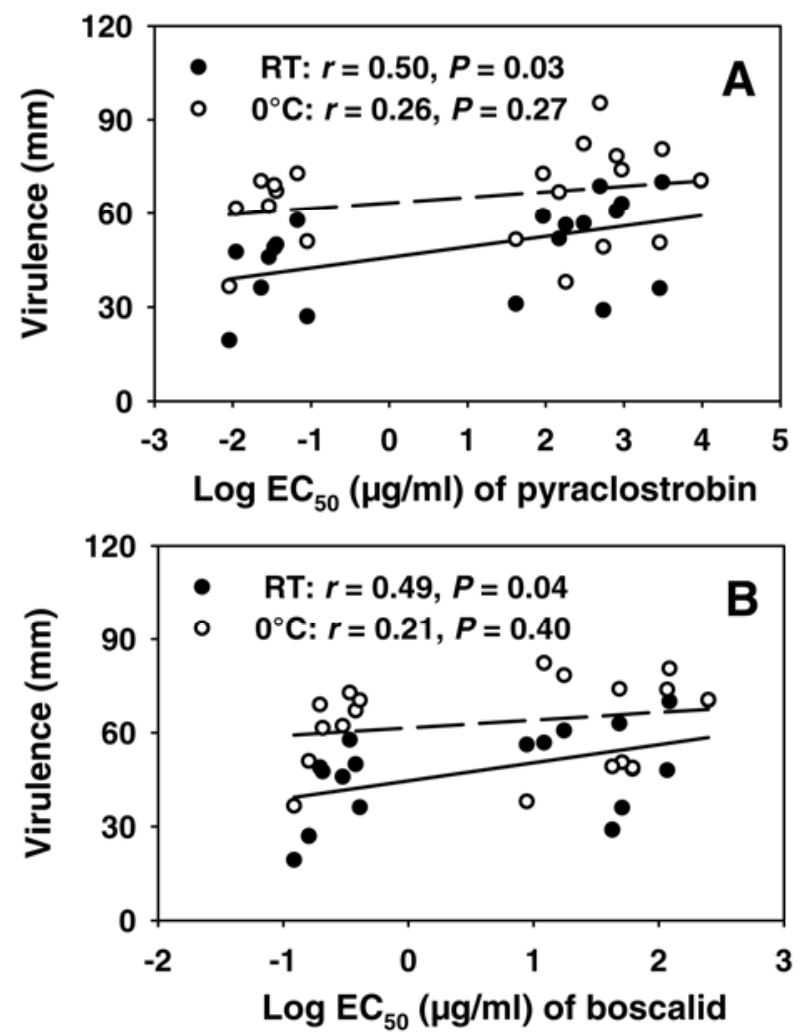

Fig. 1. Correlation between the level of fungicide sensitivity expressed as fungicide concentration resulting in $50 \%$ inhibition of fungal growth relative to the control $\left(\mathrm{EC}_{50}\right)$ values and virulence (lesion size) on apple fruit (A, pyraclostrobin and $\mathbf{B}$, boscalid) in isolates of Botrytis cinerea from apple. Open symbols, dashed line $=0^{\circ} \mathrm{C}$ and solid symbols, solid line $=$ room temperature (RT) $\left(22\right.$ to $\left.25^{\circ} \mathrm{C}\right)$. 
the first report of the stability and fitness of dual resistance to pyraclostrobin and boscalid in B. cinerea, though fitness components of pyraclostrobin resistance or boscalid resistance have previously been evaluated with laboratory-generated mutants of B. cinerea $(26,36)$. Because boscalid and other SDHI fungicides used solo or in combination with QoIs are becoming important tools for control of diseases caused by $B$. cinerea and other important fungal pathogens on various crops $(2,13)$, information on the biological and ecological characteristics of boscalid- and QoI-resistant phenotypes reported in this study will help us understand SDHI and QoI resistance in $B$. cinerea and provide a basis for developing resistance management strategies.

In our study, none of the pyraclostrobin-resistant isolates lost resistance in either in vitro or in vivo tests in the absence of the fungicide, suggesting that pyraclostrobin resistance in $B$. cinerea was stable under the experimental conditions in this study. It appears that stability of QoI resistance is pathogen dependent $(3,19,25,28,37,38)$. Our finding is different from that of a previous report indicating that laboratory UV-induced mutants of $B$. cinerea almost completely lost pyraclostrobin resistance after only seven successive transfers on fungicide-free PDA, though they rapidly regained resistance when the mutants were returned to a pyraclostrobin-containing medium (26). The discrepancy between these two studies may be due to the differences between field-resistant isolates and laboratory-induced mutants.

Boscalid-resistant isolates retained resistance to boscalid in both in vitro and in vivo tests in our study, suggesting that boscalid resistance in $B$. cinerea from apple was stable. Boscalid resistance has also been reported in $B$. cinerea from other crops in other countries $(6,23)$ but it has not been reported whether resistance is stable in $B$. cinerea isolates from these crops. Our results are similar to those of Avenot and Michailides (1), who reported that field isolates of Alternaria alternata resistant to boscalid showed no reduction in resistance after seven successive transfers on fungicide-free PDA. Furthermore, among the resistant isolates tested in our study, some were resistant to both boscalid and pyraclostrobin and retained resistance to both fungicides after successive transfers on PDA or being cycled on apple fruit, suggesting that dual resistance to pyraclostrobin and boscalid was also stable in $B$. cinerea isolates from apple under experimental conditions in our study.

Previous studies on QoI resistance indicated that the presence of fitness costs in QoI-resistant strains varied with pathosystems $(3,11,37)$. In our study, we found that saprophytic fitness components in pyraclostrobin-resistant isolates of $B$. cinerea were not impaired by pyraclostrobin resistance. However, within each phenotype group, considerable variation in saprophytic fitness parameters was observed within either resistant phenotype groups or the sensitive phenotype groups. This is likely due to the nature of great genetic variability among $B$. cinerea isolates (9). In addition, our results suggested that pathogenic fitness components tested in this study also were not impaired by pyraclostrobin resistance because pyraclostrobin-resistant phenotypes were equally pathogenic on apple fruit as the sensitive phenotype, and there was no significant negative correlation between the values of sporulation and virulence on apple fruit and the level of pyraclostrobin resistance. A previous study on the fitness of QoI resistance in laboratory-induced mutants of $B$. cinerea showed a significant reduction in sporulation, conidial germination, and sclerotia production in vitro (26). The differences in selection pressure for laboratory-induced mutants and field-resistant isolates may be responsible for the discrepancy in results between these two studies. However, similar to our results, QoI-resistant laboratory mutants or field isolates of $B$. cinerea from vegetables were also pathogenic to cucumber seedlings $(4,26)$. Taken together, these results may suggest that QoI resistance in $B$. cinerea likely does not impair pathogenicity of field-resistant isolates on host plants.
Similarly, our results also indicated that fitness components in boscalid-resistant isolates of $B$. cinerea were not impaired by boscalid resistance except that the phenotype resistant only to boscalid showed some reduction in spore production in vitro. However, this result was based only on two isolates with the pyraclostrobin-sensitive, boscalid-resistant phenotype, which were the only isolates available for this study because the vast majority of boscalid-resistant isolates obtained from apple orchards in a previous study were resistant to both pyraclostrobin and boscalid (21). Including more isolates in this phenotype group would be needed to better characterize this response. Our findings differed from those based on the laboratory-induced mutants of $B$. cinerea that boscalid-resistant mutants showed reduced pathogenicity on eggplant leaves (36). Our results were similar to those reported on field boscalid-resistant isolates of A. alternata from pistachio showing no differences between boscalid-resistant and -sensitive isolates in sporulation, spore germination, mycelial growth, and virulence in vivo (1). Although there was high variability in fitness parameters among the resistant isolates tested in the present study, similar variability also was observed among the sensitive isolates, suggesting that the variability may result from differences in the genetic background of the isolates within the same phenotype groups rather than the fitness costs, given the fact that there is great genetic variability among $B$. cinerea isolates (9). Moreover, correlation analysis also failed to find relationships between the measurements of fitness components and the level of resistance to pyraclostrobin and boscalid, except virulence at room temperature showing a weak-positive correlation with the level of resistance to both fungicides.

Although the fitness of resistant strains in the absence of the fungicide is believed to play an essential role in shaping the outcomes of competition between fungicide-resistant and -sensitive strains $(14,27)$, varying results in the competition between QoI-resistant and -sensitive strains have been observed in different pathosystems $(11,17,24)$. In our study, the increase in fungicide-sensitive individuals in the final populations regardless of the ratios of fungicide-resistant and -sensitive individuals in the initial inoculum in the competition experiment indicated that there was a competitive disadvantage of pyraclostrobin-resistant isolates of $B$. cinerea over the dual-sensitive isolate under the experimental conditions described in this study. Similar results also were observed in laboratory-induced pyraclostrobin-resistant mutants of B. cinerea (26).

Our results clearly indicated that boscalid-resistant populations of $B$. cinerea were completely overcome by a dual-sensitive isolate after four consecutive disease cycles on apple fruit, suggesting the presence of competitive disadvantage of boscalid-resistant isolates over the wild-type sensitive isolates when resistant and sensitive isolates coexisted. Measurement of fitness components in individual isolates is considered "predicted fitness", while competition between resistant and sensitive isolates is considered "realized fitness" (5). Our results suggest that, although various fitness components such as mycelial growth, conidial germination, sporulation, and pathogenicity in the absence of the fungicide are important factors in assessing the risk of build-up of fungicide-resistant populations, competitive ability of resistant strains must be evaluated in order to provide insights on the dynamics of fungicide-resistant populations because individual in vitro and in vivo fitness components may not reflect the actual outcomes of competition between resistant and sensitive strains in the pathogen populations, as we documented in this study. It should also be noted that the experiments presented in the present study were conducted either at optimal conditions for the pathogen or under constant environmental conditions. The survival of fungicide-resistant strains of $B$. cinerea and fitness components in fluctuating environmental conditions remains to be determined. Nonetheless, the information presented in this study provides insights for further understanding the biological and ecological 
characteristics of boscalid resistance and QoI resistance in $B$. cinerea.

Anti-resistance strategies are largely dependent on the use of fungicide mixture or alternations with a different mode of action or multisite fungicide to prevent or retard the development of resistance and build-up of resistant populations (12). Although both strategies have been used in practice, fungicide mixtures have become the most widely adopted resistance management strategy when fitness costs are not associated with resistance $(5,29)$. The lack of fitness penalties for various saprophytic and pathogenic components in both pyraclostrobin-resistant and boscalid-resistant phenotypes in B. cinerea, as we documented in the present study, may suggest that a mixture of pyraclostrobin and boscalid with other mode-of-action fungicides would be an option for managing QoI resistance and boscalid resistance in $B$. cinerea. Competitive disadvantage in QoI-resistant and boscalid-resistant strains of $B$. cinerea may also suggest that discontinuing use of QoIs and boscalid may help reduce resistance frequency in the pathogen populations. Because of the importance of SDHI fungicides used solo or in combination with QoIs for control of $B$. cinerea, future research is needed to monitor the dynamics of boscalid-resistant and QoI-resistant populations in fields where the fungicides are still being used or have been discontinued for use. Such information will be important to the development and implementation of fungicide resistance management practices.

\section{ACKNOWLEDGMENTS}

This research was supported, in part, by the Washington Tree Fruit Research Commission. This manuscript is Plant Pathology New Series 0569, Department of Plant Pathology, College of Agricultural, Human, and Natural Resource Sciences Agricultural Research Center, Project Number WNP00367, Washington State University, Pullman 99164-6430.

\section{LITERATURE CITED}

1. Avenot, H. F., and Michailides, T. J. 2007. Resistance to boscalid fungicide in Alternaria alternata isolates from pistachio in California. Plant Dis. 91:1345-1350.

2. Avenot, H., and Michailides, T. J. 2010. Progress in understanding molecular mechanisms and evolution of resistance to succinate dehydrogenase inhibiting (SDHI) fungicides in phytopathogenic fungi. Crop Prot. 29:643-651.

3. Avila-Adame, C., and Köller, W. 2003. Characterization of spontaneous mutants of Magnaporthe grisea expressing stable resistance to the Qoinhibiting fungicide azoxystrobin. Curr. Genet. 42:332-338.

4. Banno, S., Yamashita, K., Fukumori, F., Okada, K., Uekusa, H., Takagaki, M., Kimura, M., and Fujimura, M. 2009. Characterization of QoI resistance in Botrytis cinerea and identification of two types of mitochondrial cytochrome $b$ gene. Plant Pathol. 58:120-129.

5. Bardas, G. A., Myresiotis, C. K., and Karaoglanidis, G. S. 2008. Stability and fitness of anilinopyrimidine-resistant strains of Botrytis cinerea. Phytopathology 98:443-450.

6. Bardas, G. A., Veloukas, T., Koutita, O., and Karaoglanidis, G. S. 2010. Multiple resistance of Botrytis cinerea from kiwifruit to SDHIs, QoIs and fungicides of other chemical groups. Pest Manage. Sci. 66:967-973.

7. Bartlett, D. W., Clough, J. M., Godwin, J. R., Hall, A. A., Hamer, M., and Parr-Dobrzanski, B. 2002. The strobilurin fungicides. Pest Manage. Sci. 58:649-662.

8. Beever, R. E. 1983. Osmotic sensitivity of fungal variants resistant to dicarboximide fungicides. Trans. Br. Mycol. Soc. 80:327-331.

9. Beever, R. E., and Weeds, P. L. 2004. Taxonomy and genetic variation of Botrytis and Botryotinia. Pages 29-52 in Botrytis: Biology, Pathology and Control. Y. Elad, B. Williamson, P. Tudzynski, and N. Delen, eds. Kluwer Academic Publishers, Dordrecht, The Netherlands.

10. Brent K. J., and Hollomon, D. W. 1998. Fungicide resistance: the assessment of risk. FRAC Monogr. No. 2, Brussels.

11. Chin, K. M., Chavaillaz, D., Kaesbohrer, M., Staub, T., and Felsenstein, F. G. 2001. Characterizing resistance risk of Erysiphe graminis f. sp. tritici to strobilurins. Crop Prot. 20:87-96.

12. Edgington, L. V., Martin, R. A., Bruin, G. C., and Parsons, I. M. 1980. Systemic fungicides: A perspective after 10 years. Plant Dis. 64:19-23.

13. Fought, L., Musson, G. H., and Young, H. 2010. Luna fungicides for the control of diseases of horticultural crops. (Abstr.) Phytopathology 100:S37.

14. Fry, W. E., and Milgroom, M. G. 1990. Population biology and management of fungicide resistance. Pages 275-285 in: Management Resistance to Agrochemicals: From Fundamental Research to Practical Strategies. M. B. Green, W. K. Moberg, and H. LeBaron, eds. Am. Chem. Soc. Symp. Ser. No. 421.

15. Fungicide Resistance Action Committee. FRAC Code List: Fungicides sorted by mode of action (including FRAC Code numbering). http:// www.frac.info

16. Fungicide Resistance Action Committee. List of plant pathogenic organisms resistant to disease control agents. http://www.frac.info.

17. Genet, J., Jaworska, G., and Deparis, F. 2006. Effect of dose rate and mixtures of fungicides on selection for QoI resistance in populations of Plasmopara viticola. Pest Manage. Sci. 62:188-194.

18. Gomez, K. A., and Gomez A. A. 1984. Statistical Procedures for Agricultural Research, 2nd ed. John Wiley and Sons, New York.

19. Heaney, S. P., Hall, A. A., Davies, S. A., and Olaya, G. 2000. Resistance to fungicides in the QoI-STAR cross-resistance group: current perspectives. Proc. 2000 BCPC Conf. Pests Dis. 2:755-762.

20. Jarvis, W. R. 1977. Botryotinia and Botrytis Species: Taxonomy, Physiology and Pathogenicity. Monograph 15. Research Branch Canada, Department of Agriculture, Ottawa, Ontario, Canada.

21. Kim, Y. K., and Xiao, C. L. 2010. Resistance to pyraclostrobin and boscalid in field populations of Botrytis cinerea from apple in Washington State. Plant Dis. 94:604-612.

22. Leroux, L. 2004. Chemical control of Botrytis and its resistance to chemical fungicides. Pages 195-222 in: Botrytis: Biology, Pathology and Control. Elad et al., eds. Kluwer Academic Publishers, Dordrecht, The Netherlands.

23. Leroux, P., Gredt, M., Leroch, M., and Walker, A. 2010. Exploring mechanisms of resistance to respiratory inhibitors in field strains of Botrytis cinerea, the causal agent of gray mold. Appl. Environ. Microbiol. 76:6615-6630.

24. Ma, B., and Uddin, W. 2009. Fitness and competitive ability of an azoxystrobin-resistant G143A mutant of Magnaporthe oryzae from perennial ryegrass. Plant Dis. 93:1044-1049.

25. Malandrakis, A. A., Markoglou, A. N., Nikou, D. C., Vontas, J. G., and Ziogas B. N. 2006. Biological and molecular characterization of laboratory mutants of Cercospora beticola resistant to Qo inhibitors. Eur. J. Plant Pathol. 116:155-166.

26. Markoglou, A. N., Malandrakis, A. A., Vitoratos, A. G., and Ziogas, B. N. 2006. Characterization of laboratory mutants of Botrytis cinerea resistant to QoI fungicides. Eur. J. Plant Pathol. 115:149-162.

27. Parnell, S., Gilligan, C. A., and van den Bosch, F. 2005. Small-scale fungicide spray heterogeneity and the coexistence of resistant and sensitive pathogen strains. Phytopathology 95:632-639.

28. Pasche, J. S., and Gudmestad, N. C. 2008. Prevalence, competitive fitness and impact of the F129L mutation in Alternaria solani from the United States. Crop Prot. 27:427-435.

29. Peever, T. L., and Milgroom, M. G. 1995. Fungicide resistance-lessons for herbicide resistance management. Weed Technol. 9:840-849.

30. Raposo, R., Delcan, J., Gomez, V., and Melgarejo, P. 1996. Distribution and fitness of isolates of Botrytis cinerea with multiple fungicide resistance in Spanish greenhouses. Plant Pathol. 45:497-505.

31. Rosenberger, D. A. 1990. Gray mold. Pages 55-56 in: Compendium of Apple and Pear Diseases. A. L. Jones and H. S. Aldwinckle, eds. American Phytopathological Society, St. Paul, MN.

32. Stammler, G. 2008. Mode of action, biological performance and latest monitoring results of boscalid sensitivity. Pages 30-43 in: Abstr. 18th Symp. Res. Comm. Fungicide Resistance. The Phytopathological Society of Japan, Matsueshi, Japan.

33. Xiao, C. L., and Boal, R. J. 2009. Preharvest application of a boscalid and pyraclostrobin mixture to control postharvest gray mold and blue mold in apples. Plant Dis. 93:185-189.

34. Xiao, C. L., and Kim, Y. K. 2010. Control of postharvest diseases in apples with reduced-risk fungicides. Stewart Postharvest Review. Online publication. doi:10.2212/spr.2010.1.6

35. Zhao, H., Kim, Y. K., Huang, L., and Xiao, C. L. 2010. Resistance to thiabendazole and sensitivity to fludioxonil and pyrimethanil in Botrytis cinerea populations from apple and pear in Washington State. Postharvest Biol. Technol. 56:12-18.

36. Zhang, C. Q., Yuan, S. K., Sun, H. Y., Qi, Z. Q., Zhou, M. G., and Zhu, G. N. 2007. Sensitivity of Botrytis cinerea from vegetable greenhouses to boscalid. Plant Pathol. 56:646-653.

37. Zheng, D., Olaya, G., and Köller, W. 2000. Characterization of laboratory mutants of Venturia inaequalis resistant to the strobilurin-related fungicide kresoxim-methyl. Curr. Genet. 38:148-155.

38. Ziogas, B. N., Markoglou, A. N., and Tzima, A. 2002. A non-Mendelian inheritance of resistance to strobilurin fungicides in Ustilago maydis. Pest Manage. Sci. 58:908-916. 